\title{
Conceptualizing Loneliness in Health Research: Philosophical and Psychological Ways Forward
}

\author{
Joanna E. McHugh Power \\ Belfast; and Trinity College Dublin \\ Frank Kee \\ Queen's University Belfast
}

National College of Ireland; Queen's University

\author{
Luna Dolezal \\ University of Exeter
}

\author{
Brian A. Lawlor \\ Trinity College Dublin
}

\begin{abstract}
Increasing attention is being paid to loneliness, and to its impact on the health of older people, across numerous disciplines including psychology, public health, social policy, and psychiatry. In tandem, there has been increasing interest in the impact of social factors on health. However, definitions of loneliness are disparate, and a consensus on its meaning is arguably lacking. Often, loneliness is conflated with similar but distinct concepts such as social isolation, absence of social support, or a lack of social connectedness. We submit that the concept of loneliness requires clarification, especially in the extant health literature. We attempt to synthesize theories of loneliness provide a framework for future interventions. We further argue that the necessary clarification can be achieved using both empirical and nonempirical methodologies, under a transdisciplinary effort. We describe the potential for psychology, public health, and philosophy to come together to achieve this conceptual clarity around loneliness and to develop effective interventions on this problematic experience as a result.
\end{abstract}

Keywords: loneliness, older adults, public health, transdisciplinarity, existential phenomenology

Loneliness has been shown to be both a cause and a feature of a variety of health problems and, as such, has emerged as a substantial public health concern. Recent research has demonstrated that loneliness is linked to many undesirable health outcomes, including early mortality risk (Holt-Lunstad, Smith, Baker, Harris, \&
Stephenson, 2015), cardiovascular mortality, increased blood pressure and risk of incident coronary heart disease and stroke (L. C. Hawkley, Thisted, Masi, \& Cacioppo, 2010; Thurston \& Kubzansky, 2009), accelerated ageing (L. C. Hawkley, Preacher, \& Cacioppo, 2007), increased risk of incident dementia and cognitive
Joanna E. McHugh Power, School of Business, National College of Ireland; UK CRC Centre of Excellence in Public Health, Queen's University Belfast; and Institute of Neuroscience, Lloyd Building, Trinity College Dublin. Luna Dolezal, Medical Humanities, University of Exeter. Frank Kee, UK CRC Centre of Excellence in Public Health, Queen's University Belfast. Brian A. Lawlor, Institute of Neuroscience, Lloyd Building, Trinity College Dublin.

The authors wish to acknowledge the Trinity Long Room Hub for inviting Joanna E. McHugh Power to pres- ent a preliminary version of the current manuscript in their seminar series, and the audience of this seminar, who offered many useful comments.

This article was developed during a Leadership in Ageing Research Fellowship received by the corresponding author from the Centre for Ageing Research and Development in Ireland (CARDI).

Correspondence concerning this article should be addressed to Joanna E. McHugh Power, School of Business, National College of Ireland, Room 2.16, I.F.S.C., Mayor Street, Dublin 1, Ireland. E-mail: mchughje@tcd.ie 
decline (J. T. Cacioppo \& Hawkley, 2009; Wilson et al., 2007), increased health care service utilization (L. C. Hawkley \& Cacioppo, 2010), and increased risk of depression and suicidality (J. T. Cacioppo et al., 2006; Green et al., 1992; Jackson \& Cochran, 1991; Lykes \& Kemmelmeier, 2014). It is no wonder, then, that loneliness has been hitting international headlines as an "epidemic" (New York Times), the "next big global health problem" (Irish Times), the "next big public health issue" (Time), and as "big a killer as obesity and as dangerous as smoking" (Daily Express, United Kingdom).

Despite the clear significance of loneliness for health outcomes, it is defined in divergent ways across the humanities, social sciences, and medical literatures and unsurprisingly is seen to have different effects in different contexts. Studies of loneliness, from various disciplinary perspectives, have been concerned with measuring many diverse conditions and attributes, and this breadth of interest has introduced significant ambiguities in the meanings attributed to health-related loneliness. As a practical matter, conceptual clarity is crucial when measuring its frequency and when designing and delivering interventions to mitigate or eliminate experiences of loneliness in order to improve health.

The aim of this article is, first, to demonstrate the heterogeneity of definition in current loneliness research and to attempt a theoretical synthesis of the leading approaches to understanding loneliness. Second, we describe the limited effectiveness of interventions, which, we argue, is a direct consequence of the heterogeneous nature of current definitions. Third, to address the conceptual muddiness that surrounds the term "loneliness" within health research, we propose a research agenda that offers some possible ways forward. We contend that some conceptual elaboration using philosophical phenomenology, as well as more empirical qualitative and mixed methods work, will have complementary value in further developing the concept of loneliness inductively. We argue that both philosophical and empiricist perspectives on loneliness must come together via transdisciplinary research to offer a full understanding of what may be a complex phenomenon or set of phenomena. We conducted this work in a postpositivist, pluralist manner because loneliness itself is polysemous and can connote multiple meanings.

\section{Theoretical Synthesis}

We conducted a theoretical synthesis using established methods as exemplified by the work of Bonell and others (Bonell et al., 2016; Houlihan, 2018). Theory synthesis allows the researcher to compare and integrate across theories (Pound \& Campbell, 2015). We aimed, using this method, to develop a causal understanding of loneliness, in an update of a theoretical review conducted 30 years ago (Marangoni \& Ickes, 1989). Although attempts to integrate existing theories of loneliness have been made since (Jenny de Jong Gierveld, 1998; Heinrich \& Gullone, 2006; Ong, Uchino, \& Wethington, 2016; Sønderby \& Wagoner, 2013; Stein \& Tuval-Mashiach, 2015), we contend that these attempts have not been comprehensive, most frequently omitting biological accounts of loneliness, and additionally, many constitute reviews without rigorous syntheses of theory.

According to Pound and Campbell (2015) and Houlihan (2018), there are three steps in theory synthesis: (a) synthesis preparation (parts of relevant theories are extracted and summarized), (b) synthesis (compare theories for points of divergence and convergence), and (c) synthesis refinement (interrogate synthesis further for theoretical insights). In what follows, we execute these three steps and present our synthesized model of the etiology of loneliness.

We first used a systematic search strategy to locate the relevant theories. We conducted our searches using PsycINFO and Scopus (similar to Wong \& Rapee, 2016). The search terms were lonely, loneliness, theory, theoretical, and model ([loneliness OR lonely] AND [theory OR theoretical OR model]). Our inclusion criteria were written in English, for the years 1900 to 2018, and the literature was restricted to systematic reviews or literature reviews or meta analyses (in Scopus, findings were restricted to reviews and book chapters). Literature was then screened to determine relevance. The PsycINFO search yielded 70 results. The Scopus search yielded 233 results. We extracted data from each article on aim, description of theory, and links to other theories (in a similar manner to work done previously, e.g. Bonell et al., 2016 and also Michie \& Prestwich, 2010).

We then used template analysis to synthesize theoretical literature - we first developed a tem- 
plate and used this to code two theoretical articles to initiate the process of refining theoretical constructs within the template in light of their articulation in the articles and explaining in memos the rationale for doing so. The template is developed to include the theoretical constructs already known to the researchers, and this was then iteratively enhanced and used to code the subsequent eligible theoretical articles, aiming for saturation until no new theoretical constructs can be integrated. Our initial template was thus a preliminary integrative analysis of theories of loneliness (Sønderby \& Wagoner, 2013), which delineates causes of loneliness being the following: lack of intimacy, cognitive discrepancy, confused response to Western society, and lack of emotional or social relations (we divided this last one into two). This schema was then applied to each subsequent theoretical article that was deemed relevant and eligible from the 303 results initially found at literature search stage. Memos were written to explain the refinement of each theoretical construct in response to each new article that was evaluated.

There were a total of 38 relevant articles explored and integrated for the theoretical synthesis. We extended and updated the template article (Sønderby \& Wagoner, 2013) using a theoretical synthesis approach and arrived at the following model (Figure 1). This model builds upon and extends beyond those described previously in the literature, providing a comprehensive description of the theoretical components of loneliness. This model echoes Peplau and Perlman, who stated that the best approach to understanding loneliness would take into account "the cellular to the international" (p. 129) (Peplau \& Perlman, 1982).

In the following text, we discuss each level of the abovementioned model in turn, before considering how our model maps on to previous theories. For the most part, we cite previous

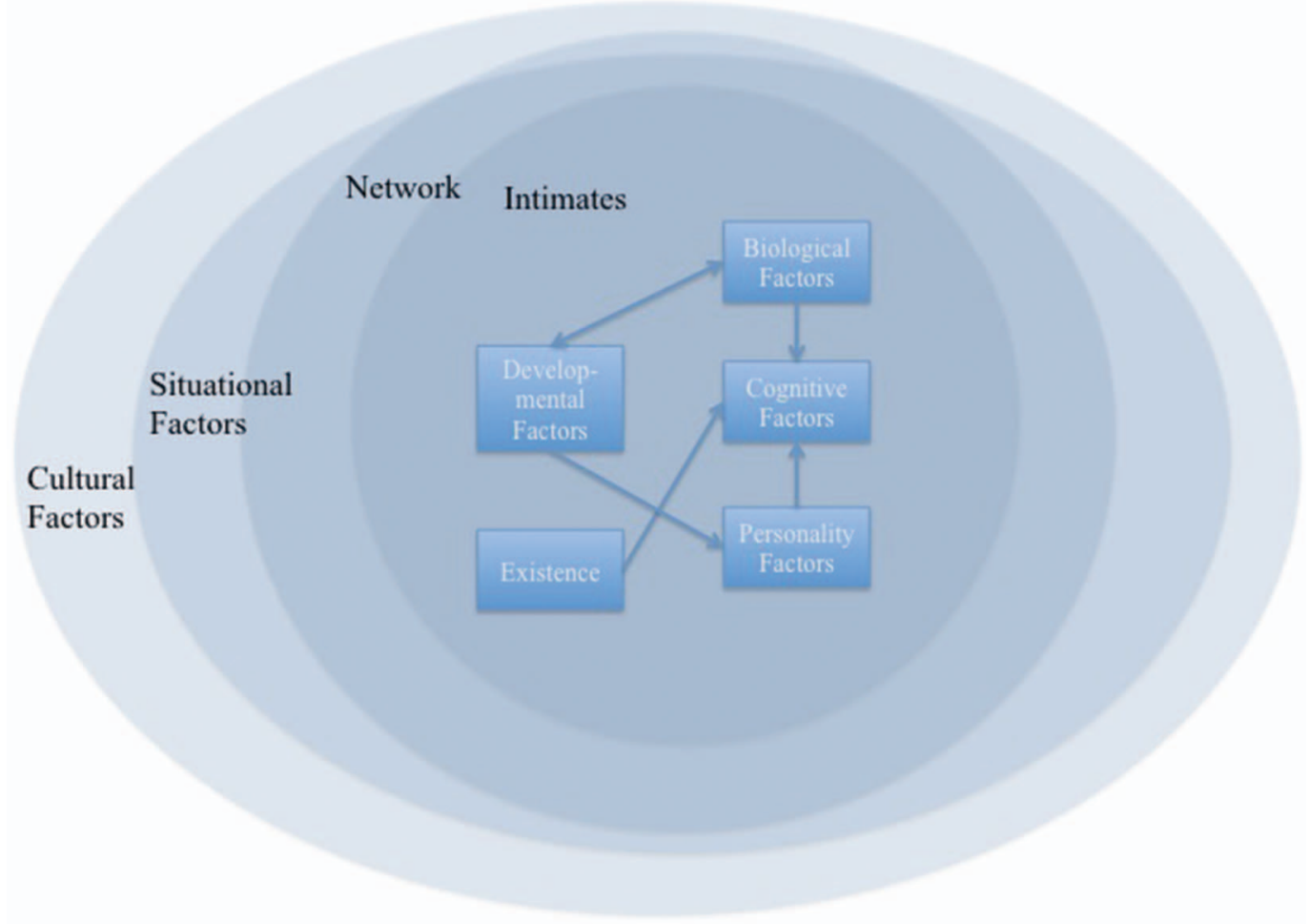

Figure 1. Synthesized model of loneliness as constituting five intraindividual levels (biological, developmental, cognitive, personality factors, and existence) and four interindividual and societal levels (intimates, network, situational factors, and cultural factors). See the online article for the color version of this figure. 
reviews that describe each component of loneliness causation, rather than individual studies (because we are aiming at synthesizing theories rather than synthesizing empirical findings).

\section{Existence}

Mostly arising from philosophical literature comes the idea that mere existence and the accompanying acknowledgment of death are sufficient to cause loneliness (Bekhet, Zauszniewski, \& Nakhla, 2008; Gardiner, Geldenhuys, \& Gott, 2018; Mayers \& Svartberg, 2001; Moustakas, 1961; Rosedale, 2007). These ideas arise from existential philosophy and existential phenomenology and are described in the work of Heidegger and Sartre (Mayers \& Svartberg, 2001). Typically this type of loneliness has been described as "existential loneliness," which may or may not overlap with the loneliness concept described in the remainder of the synthesis. It is possible that the propensity to experience loneliness as a result of existential reflection underlies all subsequent loneliness described in the following text.

\section{Personality and Affective Factors}

Personalities with tendencies toward negative beliefs and behaviors about the self and about others were described across the literature as causes of loneliness. Specifically, factors such as pessimism about others (Mikulincer \& Shaver, 2014), shyness and self-consciousness (Heinrich \& Gullone, 2006; Mahon, Yarcheski, Yarcheski, Cannella, \& Hanks, 2006; Marangoni \& Ickes, 1989), introversion (Heinrich \& Gullone, 2006), sociability and talkativeness (Marangoni \& Ickes, 1989), extent of affiliation needs (Heinrich \& Gullone, 2006), selfdisclosure tendencies (Derlega \& Margulis, 1982; Heinrich \& Gullone, 2006; Mahon et al., 2006), difficulty forming relationships (Marangoni \& Ickes, 1989), poor social skills (Mahon et al., 2006; Marangoni \& Ickes, 1989; Wong, Yeung, \& Lee, 2018), neuroticism (Zysberg, 2015), high standards for others (J. de Jong Gierveld \& Tesch-Romer, 2012; Marangoni \& Ickes, 1989), external locus of control (Heinrich \& Gullone, 2006; Perlman, 2004), engagement in social comparison (Perlman, 2004), social anxiety (Mahon et al., 2006), emotional regulation (Wong et al., 2018; Zysberg, 2015), profi- ciency in processing of social information (Spithoven, Bijttebier, \& Goossens, 2017), selfconcept (Marangoni \& Ickes, 1989; Zysberg, 2015), interpersonal coldness (J. T. Cacioppo \& Hawkley, 2009), cynicism, misanthropy, and hostility (Heinrich \& Gullone, 2006) were all factors that fell under this heading. Zysberg suggested that a "lonely" personality may exist (Zysberg, 2015) — based on the earlier text, this individual would feel themselves to be unlovable, have a poor sense of self with poor social skills, high neuroticism, low extraversion, deficits in self-disclosure, emotion regulation, social information processing, and relationship formation. To others, the individual may appear shy, unsociable, self-conscious, cynical, misanthropic, and hostile.

\section{Cognitive Factors}

Deriving mainly from the cognitive discrepancy model (Daniel Perlman \& Peplau, 1982), much has been written about the cognitive factors determining loneliness. Some of these refer to cognitions about the self, and some refer to cognitions about others. These cognitions include self-blame (Heinrich \& Gullone, 2006), poor self-esteem (Ayalon, Shiovitz-Ezra, \& Palgi, 2012; Jenny de Jong Gierveld, 1998; Heinrich \& Gullone, 2006; Kupersmidt, Sigda, Sedikides, \& Voegler, 1999; Mahon et al., 2006; Marangoni \& Ickes, 1989; Mayers \& Svartberg, 2001), dysfunctional attributions about others (Galanaki \& Vassilopoulou, 2007; Heinrich \& Gullone, 2006; Marangoni \& Ickes, 1989; Perlman, 2004; Spithoven et al., 2017; Zysberg, 2015), negative perceptual biases/ hypervigilance for social threats (J. T. Cacioppo \& Hawkley, 2009; Marangoni \& Ickes, 1989), learned helplessness (Heinrich \& Gullone, 2006), perceived discrepancies about the self (relative to the ideal self; Heinrich \& Gullone, 2006) and about relationships (relative to the ideal relationships; Marangoni \& Ickes, 1989; Daniel Perlman \& Peplau, 1982), lack of "just world" beliefs (Heinrich \& Gullone, 2006), maladaptive social cognitions (J. T. Cacioppo \& Hawkley, 2009; L. C. Hawkley \& Capitanio, 2015; Masi, Chen, Hawkley, \& Cacioppo, 2011; Spithoven et al., 2017), inadequate mental scripts for coping with stress (Mikulincer \& Shaver, 2014), negative evaluations of self and others (J. de Jong Gierveld \& Tesch-Romer, 
2012; Spithoven et al., 2017; Wong et al., 2018), tendency to avoid taking social risk (Heinrich \& Gullone, 2006), poor sense of coherence (Rokach, Rosenstreich, \& Matot, 2015), and a failure to make meaning of life (Mayers \& Svartberg, 2001; Rosedale, 2007).

According to the cognitive discrepancy model, which has arguably been the most influential model within loneliness research, loneliness arises because there is a discrepancy between actual and desired relationships (Daniel Perlman \& Peplau, 1982). However, it is clear that research within the cognitive psychological domain has revealed that loneliness is more complex than this, arising from largely dysfunctional beliefs about the world, about others, and about the self, which serve to reinforce loneliness and isolation from others by negatively impacting existing and potential relationships (L. C. Hawkley \& Capitanio, 2015). Attempts have been made to reconcile this characterisation of loneliness as predominantly dysfunctional with the concept of loneliness as being adaptive, and serving to bring individuals closer together (J. T. Cacioppo, Cacioppo, \& Boomsma, 2014; J. T. Cacioppo \& Hawkley, 2009; Qualter et al., 2015) by Qualter and her colleagues (2015). Qualter suggests that while transient loneliness may service to activate the "re-affiliation motive", and thus be adaptive, dysfunctional cognitions which may be adaptive also in the short-term become counterproductive in the long-term, i.e., if loneliness becomes chronic (Qualter et al., 2015; S. Cacioppo, Capitanio, \& Cacioppo, 2014).

\section{Biological Factors}

The influence of biology on loneliness can be viewed from a number of levels. Evolutionary theory of loneliness puts forward that loneliness has been piggybacked on phylogenetically older neural substrates of pain, to encourage the individual to avoid becoming isolated and to reconnect with others (J. T. Cacioppo et al., 2014; J. T. Cacioppo et al., 2006). Accordingly, evolution has shaped a heritable sensitivity toward social rejection, leading to increased likelihood of loneliness (Boomsma, Willemsen, Dolan, Hawkley, \& Cacioppo, 2005). At the individual level, then, changes in brain regions appear to subserve loneliness. Specifically, changes to the neural substrates of social processes, such as mentalizing/theory of mind and social cognitions, appear to be implicated in loneliness ( $\mathrm{S}$. Cacioppo, et al., 2014). Differential signaling in areas of the brain related to social reward such as the ventral striatum and in areas related to social rejection such as the anterior cingulate cortex and the anterior insula, as well as the dorsal raphe nuclei, also may be implicated in loneliness (J. T. Cacioppo et al., 2000; Eisenberger, Lieberman, \& Williams, 2003; Matthews et al., 2016; Wong et al., 2018).

Taken together, these studies indicate that loneliness is an adaptive biological mechanism that serves to endorse reaffiliation among temporarily isolated individuals, but which may go awry when allowed to become chronic. However, many of the studies conducted in this domain are animal studies, and as such, loneliness is inferred from a state of social isolation. In many of the abovementioned studies, loneliness among humans too is defined as perceived social isolation, which may fail to account for the complex existential, personality, affective, and cognitive aspects of the phenomenon. Biological processes could, however, be made compatible with these aspects of loneliness if they were taken to represent the evolutionary, genetic, and neurobiological contexts in which the more complex phenomenon of loneliness might arise.

\section{Developmental Deficits}

Approaches to discussing the developmental factors that cause loneliness have arisen across two main disciplines: psychoanalytic theory and social neuroscience. In the former, the focus has mainly been on issues of early attachment, the idea being that an anxious or avoidant early attachment can make an individual susceptible to adulthood loneliness (Bowlby, 1973; FrommReichmann, 1959; Galanaki \& Vassilopoulou, 2007; Mayers \& Svartberg, 2001; Mikulincer \& Shaver, 2014; Rokach et al., 2015; Sullivan, 1953; R. Weiss, 1974). The characteristics of caregivers in early life such as parental loneliness and expressiveness (Kupersmidt et al., 1999; Mahon et al., 2006), social support during childhood and adolescence (Mahon et al., 2006), and the infant developmental task of individuating from the parent (Rosedale, 2007) were also linked to later feelings of loneliness. Adult attachment style is also associated with 
loneliness (Mikulincer \& Shaver, 2014). Attachment theory more generally is compatible with the evolutionary approach to biology because Bowlby also described attachment as an adaptive process (Bowlby, 1973). A more recent attempt was made to integrate attachment theory and social neuroscience by describing the process of adolescent brain development as underlying the experience of loneliness: Brain regions related to social signal processing are stronger than typically dampening cognitive and executive areas during adolescence, and as such, the developing brain is particularly sensitive to social cues and resulting feelings of social rejection and loneliness (Wong et al., 2018).

The following factors found to be important in the etiology of loneliness are outside of the individual and can be thought of as representing similar levels of influence as those found in the ecological systems theory of development (Bronfenbrenner, 1992). That is, it is expected that there will be interactive impacts between each of the subsequent factors and that each subsequent factor represents a context for the preceding factors to have their effects.

\section{Intimates}

The discussion of the importance of an intimate attachment figure stems from the seminal work of Weiss and Bowlby (Bowlby, 1973; R. S. Weiss, 1973). Weiss describes emotional loneliness as arising from the absence of a significant intimate figure, such as a spouse. Other theorists also attribute loneliness to the loss or absence of an intimate other (Ayalon et al., 2012; J. de Jong Gierveld \& Tesch-Romer, 2012; Zysberg, 2015). Perlman suggests that this tendency is stronger in public health research than in psychological research (the latter tending to discuss more distal, intrapersonal influences on loneliness; Perlman, 2004). Others have attributed loneliness to an inadequate level of intimacy within the primary attachment relationship in adulthood (Galanaki \& Vassilopoulou, 2007; Sullivan, 1953; R. Weiss, 1974).

\section{Network and Network Deficits}

Much of the focus in defining loneliness has been on the importance of others in the social network. The network provides a context for relationships to develop, of both intimate and non-intimate nature. Many theorists have defined loneliness as constituting a deficit or aberration in the characteristics of the social network, including perceived social isolation $(\mathrm{J} . \mathrm{T}$. Cacioppo \& Hawkley, 2009); feeling apart or distant from others (Bekhet et al., 2008; Tzouvara, Papadopoulos, \& Randhawa, 2015), resulting from a change or absence of friendships (Galanaki \& Vassilopoulou, 2007; Kupersmidt et al., 1999; Marangoni \& Ickes, 1989); size of network (Marangoni \& Ickes, 1989; Rokach et al., 2015), low social status within the network (J. de Jong Gierveld \& Tesch-Romer, 2012); interpersonal conflict (J. de Jong Gierveld \& Tesch-Romer, 2012; Galanaki \& Vassilopoulou, 2007), social withdrawal and disengagement (Ayalon et al., 2012; Heinrich \& Gullone, 2006; Kupersmidt et al., 1999; Qualter et al., 2015); and extent of social interaction (Heinrich \& Gullone, 2006; Mahon et al., 2006; Marangoni \& Ickes, 1989). Other types of network deficit described as causing loneliness include a lack of fulfilling relationships (Zysberg, 2015), lack of social support (ElSadr, Noureddine, \& Kelley, 2009; Mahon et al., 2006; Marangoni \& Ickes, 1989; Rokach et al., 2015; R. Weiss, 1974), validation of worth (Heinrich \& Gullone, 2006; Rosedale, 2007), provision of shared meaning (Rosedale, 2007; Sullivan, 1953), guidance from others, reliable alliance (R. Weiss, 1974), and a sense of empathic understanding (van Staden \& Coetzee, 2010).

Clearly, from the extent of literature regarding the impact of network on loneliness, etiology extends outside of the individual. Again, there is clear evidence that personal and network factors interact to produce loneliness. For instance, beliefs about oneself and about others will in part shape the social network surrounding an individual, and the existence of loneliness can shape social interactions to such an extent that an individual becomes marginalized in their network (J. T. Cacioppo, Fowler, \& Christakis, 2009). The impact of network-level factors on an individual's cognitions, affect, and personality is less of a focus within the psychological literature, as personal factors and resultantly personal responsibility are mostly seen as causal here (Perlman, 2004). Failure to account for societal-level influences on loneliness leads to an incomplete theory of its etiology ( $\mathrm{J}$. de Jong Gierveld \& Tesch-Romer, 2012). 
We will consider now the last two factors influencing loneliness that speak to this point: situational factors and cultural factors.

\section{Situational Factors}

Situational factors set a context in which loneliness is more or less likely to occur. Factors such as illness (Jenny de Jong Gierveld, 1998; Scharf \& de Jong Gierveld, 2008); low income (Ong et al., 2016; R. Weiss, 1974); low educational attainment (Ong et al., 2016); contextual changes such as hospitalization, immigration, institutionalization, or incarceration (Jenny de Jong Gierveld, 1998; ElSadr et al., 2009; R. Weiss, 1974); rural living (Zysberg, 2015); and physical, cognitive, or sensory disability (Ayalon et al., 2012) have all been linked to increased levels of loneliness. Again, it is likely that these factors set the scene for more proximal influences on loneliness: Cognitive disability, for instance, may create embarrassment and as such initiate social withdrawal, which in turn causes loneliness (Ballard, 2010), whereas having low income may create strain on existing relationships, leading to relationship breakdown and resulting loneliness (J. de Jong Gierveld \& Tesch-Romer, 2012). An individual with poor health and disability and low income, possibly experiencing a change in living circumstances, may be more likely to experience loneliness, and this in turn may explain the later-life spike in loneliness levels.

\section{Cultural and Societal Factors}

Many situational factors are influenced in turn by cultural and societal level factors. In addition, cultural influences on individual factors may help to shape some of the more proximal influences on loneliness, such as cognitive and affective factors. Individualistic societies that promote the well-being of the individual over the good of the group or the collective may be more prone to loneliness in general (Slater, 1970; Sønderby \& Wagoner, 2013), although other theorists and empirical research suggest the opposite (DiTommaso, Brannen, \& Burgess, 2005; Johnson \& Mullins, 1987; van Tilburg, Havens, \& de Jong Gierveld, 2004). Cultural factors more generally have been suggested to shape loneliness (R. Weiss, 1974) and may shape the social norms that in turn influence an individual's evaluation of their existing relationships and subsequent loneliness (van Staden \& Coetzee, 2010), such as filial norms and familialism (J. de Jong Gierveld \& TeschRomer, 2012). For instance, individuals may have a threshold of acceptable social interaction, beyond which they will experience loneliness (Johnson \& Mullins, 1987), and this threshold may in part be culturally determined.

Cultures may create different forms of loneliness (van Staden \& Coetzee, 2010), although loneliness is thought to be universal in that it has been reported in every culture investigated (Perlman, 2004). Culture may either influence desired or actual levels of social contact (Perlman, 2004). Loneliness may constitute a social construction and as such be entirely contingent on culture, which would contradict the biological approach to explaining loneliness (Schirmer \& Michailakis, 2016). The political context of a country can influence loneliness too, with people in countries experiencing turmoil or recent change most prone to loneliness (J. de Jong Gierveld \& Tesch-Romer, 2012; Iecovich et al., 2004; Zysberg, 2015). Distribution of wealth may partly influence loneliness because a lack of financial resources can cause loneliness for reasons delineated earlier in Situational Factors (J. de Jong Gierveld \& TeschRomer, 2012).

In Table 1, we evaluate each of the commonly described approaches in loneliness research in light of the synthesized model and demonstrate that each of these approaches is incomplete and somewhat compatible with the other approaches mentioned. Theories did not contradict each other outright, and thus we were able to develop a comprehensive synthesized theory of loneliness and its causes. Specifically, it should be clear that loneliness arises because of factors at multiple levels of functioning, some of which interact with each other. To evaluate an individual's likelihood of developing loneliness, evaluations of functioning could take place at each of these levels. Similarly, in developing interventions for loneliness, all levels should be taken into account.

\section{The Problem of Intervention}

Public health science is calling out for evidence-based treatments for loneliness (Michie \& Prestwich, 2010; O'Luanaigh et al., 2012). 


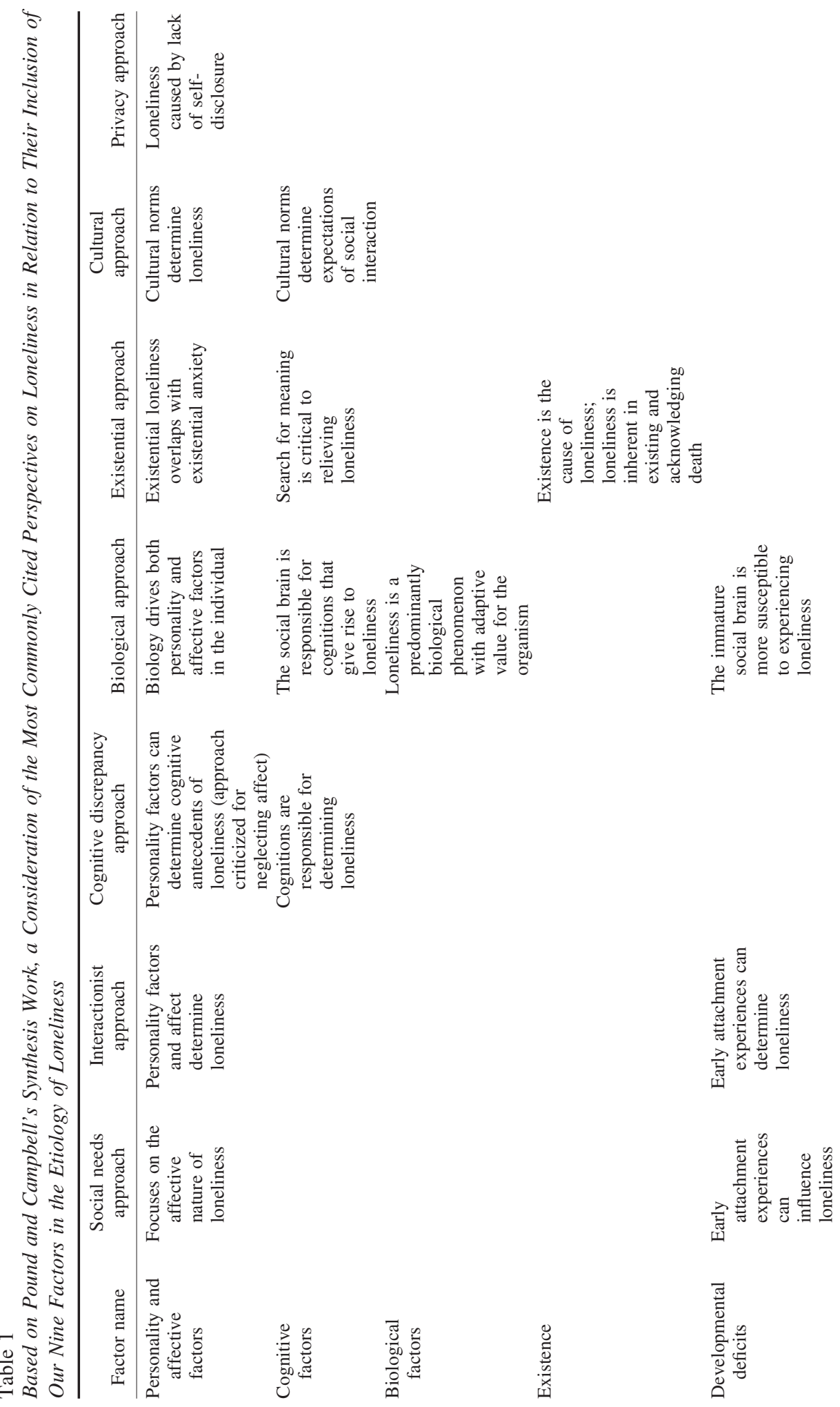




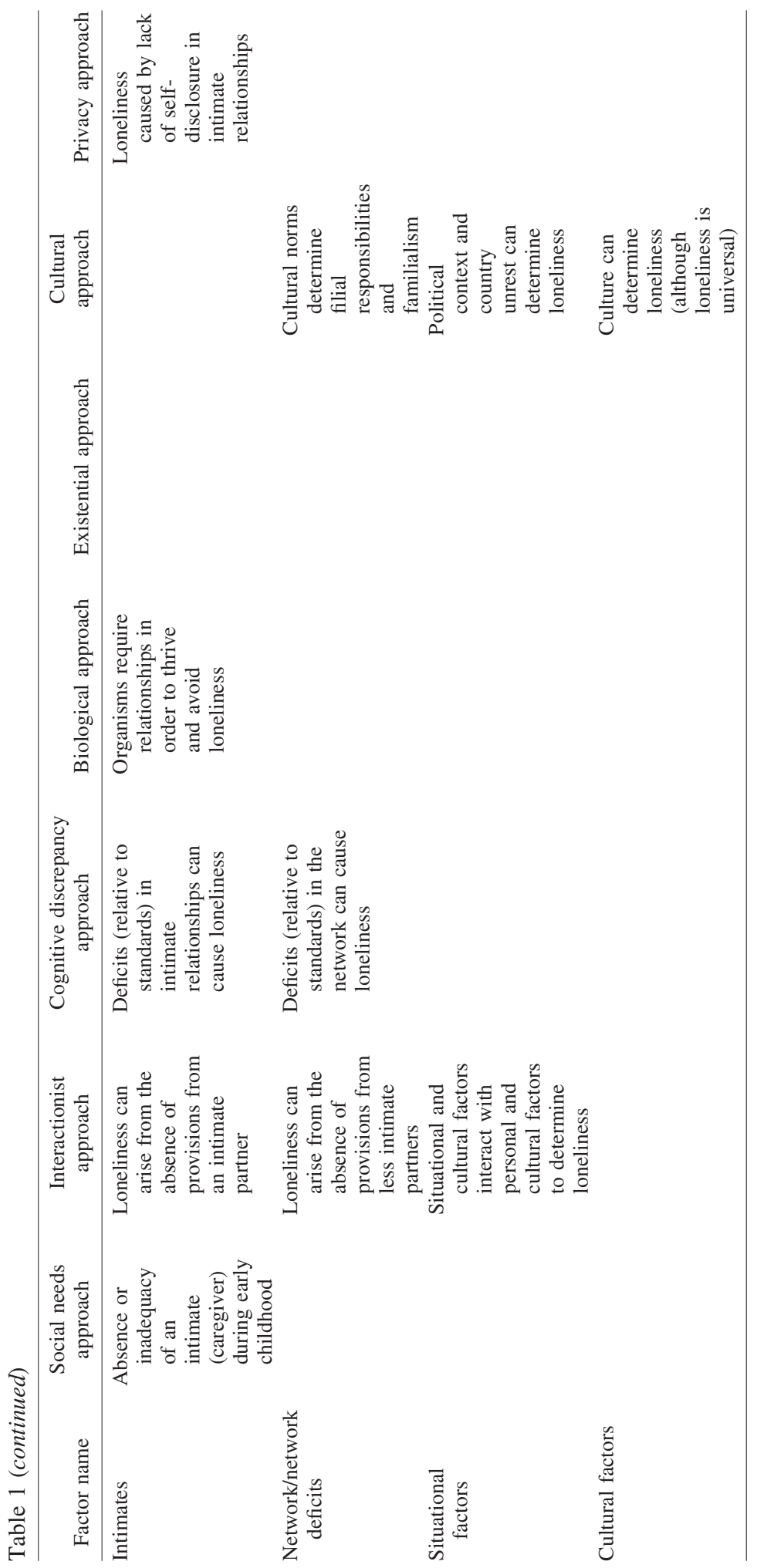


Although public health interventions to prevent or "cure" loneliness have been developed, their effectiveness has been variable. It has previously been stated that the theoretical aspects of loneliness research have been saturated, and it is now time to focus on the development of loneliness interventions (L. Theeke, 2009). Indeed some recent interventions have had success in reducing loneliness, using cognitive-behavioral methods and befriending services (Lawlor et al., 2014; L. A. Theeke et al., 2016).

Notwithstanding this, we note that we still have no consensus on its definition and measurement. Nevertheless, there is a relative dearth in adequate evidence-based treatments for loneliness (O'Luanaigh, et al., 2012). These have fallen into four main categories (L. C. Hawkley \& Cacioppo, 2010): the enhancement of social skills, addressing of maladaptive social cognitions, increasing opportunities for social interaction, and the provision of social support.

Interventions taking these approaches have had mixed impacts, and there remains considerable disagreement concerning the best way to intervene upon loneliness (Findlay, 2003). This disagreement is an inevitable consequence of a lack of consensus on a definition, as intervention approaches might change depending on the approach to definition being taken. For instance, researchers adopting the cultural approach to loneliness would aim to encourage better feelings of connectedness to one's culture, whereas those adopting the social needs approach would aim to minimize social isolation for participants in an attempt at reducing loneliness.

A separate but related issue is the importance of adequate measurement of loneliness. Different measures are currently in use within public health and psychological research-some treat loneliness as a unidimensional construct, whereas others acknowledge a bidimensional or multidimensional structure. Better, more consensus-based measurements of loneliness would positively impact the homogeneity within metaanalyses and would also help to evaluate success of interventions (Terwee et al., 2012).

\section{Integrating the Various Approaches Through Transdisciplinarity}

Partly, the heterogeneity of definitions described earlier, and their implications for interventions, can be attributed to disciplinary dif- ferences. The approaches to loneliness span the disciplines of psychology, psychiatry, geriatric nursing, public health and general practice, social policy, and sociology, and it would seem be beneficial if a common definition was shared across disciplines, in a truly transdisciplinary fashion. In addition, variations in definition may reflect changes in conceptualization over time because definitions have shifted from a focus on objective isolation states toward more subjective experiences, and from loneliness as a pathological experience to a more normative experience (Nilsson, Lindström, \& Nåden, 2006; Stein \& Tuval-Mashiach, 2015).

Transdisciplinarity has been successfully applied to health research (Choi \& Pak, 2006) as the approach can

resolve real world or complex problems, to provide different perspectives on problems, or create comprehensive research questions, to develop consensus clinical definitions and guidelines, and to provide comprehensive health services. (p. 351)

As such, forging a mutually agreed definition, or conceptual model of loneliness across the fields of psychology, sociology, medicine and social policy, would be of use to all domains, at least providing new perspectives that might help us arrive at consensus on effective ways to intervene to improve outcomes. This point has previously been made by those who have advocated the use of needs assessments to define and understand the problem prior to intervention design (Wight, Wimbush, Jepson, \& Doi, 2015). The current synthesized model of loneliness could constitute a starting point in informing interventions in this manner. It must be said that theory-based interventions do not necessarily constitute effective interventions, however (Prestwich et al., 2014).

\section{Empirical Ways Forward}

As we stated earlier, there is "fuzziness" to the manner in which social factors are being defined at the interface between social science and medicine. We argue that this same fuzziness applies to loneliness, which often is conflated with concepts such as social isolation, social support, and social relationships. As recently as 2016, loneliness was being included in models as the subjective end of social functioning (Valtorta, Kanaan, Gilbody, Ronzi, \& Hanratty, 2016), whereas this would contradict 
some of the approaches described earlier, which posit that loneliness is not solely related to social factors.

We have tried to contend with this conceptual fuzziness by synthesizing existing theories of the etiology of loneliness. Another way that we can try to reduce conceptual fuzziness is through the use of inductive, qualitative, and exploratory research. By using qualitative methods, we can allow data to guide theoretical development of loneliness as a concept. This will complement the attempt to describe the etiology of loneliness, by explaining the subjectivity of loneliness. However, relatively few studies have used qualitative methods to explore the concept of loneliness. In 1988, a content analysis was conducted on written responses to the question "Please describe your loneliest experience" and found four facets of loneliness: self-alienation, interpersonal isolation, distressed reactions, and agony (Rokach, 1988). A reflective lifeworld approach also investigated personal conceptualization of loneliness and found that it was described as being the figure in the background of fellowship, connectedness, and context (Dahlberg, 2007). In this analysis, loneliness was seen as being something that arose out of a feeling of being different to others in manners that felt strange, shameful, or taboo.

Our own qualitative investigations into loneliness, using interpretative phenomenological analysis, showed that loneliness was not frequently associated with social isolation for individuals, and when asked what loneliness meant for them, only two out of 13 individuals referred to social isolation or aloneness. Most individuals spoke of loneliness as meaning boredom, a lack of physical and personal security, shame, a lack of activity, and as something that varied according to place, such that urban areas were the loneliest (McHugh Power, Hannigan, Carney, \& Lawlor, 2017). The clear discrepancy between what individuals report their experiences of loneliness to consist of and how it is described in current health research indicates that there is a pressing need for a more nuanced understanding of the concept.

\section{Nonempirical Ways Forward}

Research into interventions for loneliness must be based on a well-clarified conceptual model of loneliness (O’Luanaigh et al., 2012). There is a pressing need for conceptual clarity that is grounded in what individuals experience as loneliness, rather than on prototypical or stereotypical understandings of the concept, and we believe that a philosophical phenomenology approach will help clarify the path to such a model

Although a number of qualitative methods in psychology, sociology, and other social sciences purport to take a "phenomenological" approach, the meaning of the term varies significantly across disciplines. In psychology, for instance, "phenomenology" is used to refer to subjective experiences that can be described through introspection (Paley, 2016), and a number of empirical qualitative approaches use phenomenological methodologies under this understanding (Pietkiewicz \& Smith, 2014).

Although there is no comprehensive phenomenological account of loneliness at present, philosophical phenomenology is an approach that has been used to describe a range of phenomena related to loneliness and its opposites, such as intersubjective constitution (Husserl, 1977; Merleau-Ponty, 2012; Sartre, 2003; Zahavi, 2014), sociality and the "we" experience (Salice \& Schmid, 2016; Szanto \& Moran, 2016), social encounters (Dolezal \& Petherbridge, 2017), solitary confinement (Gallagher, 2014; Guenther, 2013), shame (Dolezal, 2015), depression (Ratcliffe, 2014), and solitude (Levinas, 1987). Although it is clear that further phenomenological investigation is required to construct a conceptual model of loneliness within lived experience, the existing literature already provides rich conceptual resources through which the various facets of the experience of loneliness might be conceptualized. At present, very little of the existing health research draws upon this literature.

A number of emerging approaches are combining the theoretical approach of philosophical phenomenology with the empirical method of the qualitative interview (Aspers, 2009; Høffding \& Martiny, 2016; Parnas et al., 2005). When considering complex experiential phenomena such as loneliness, these interdisciplinary approaches are a pathway with the potential to yield the sort of transdisciplinary insights that are necessary for effective health research and interventions. 


\section{Conclusion}

We have argued that loneliness is insufficiently operationalized, defined, and conceptualized, not just across disciplines but also within them. We have highlighted some of the ramifications of this. Specifically, it will be difficult to understand the true impact of loneliness on health, the mechanisms through which it operates, and the interventions that best stand to alleviate it, without a clear and evidence-based conceptualization of loneliness and agreement on its ontology. We present ways forward and offer a theoretical synthesis methodology to bring together ideas on the etiology of loneliness. We advocate the use of qualitative methods to further characterize the subjective experience of loneliness, exploiting, and in tandem with, a transdisciplinary psychological-philosophical approach that will ultimately go some way toward explaining how and why it impacts upon physical health outcomes.

\section{References}

Aspers, P. (2009). Empirical phenomenology: A qualitative research approach. The Indo-Pacific Journal of Phenomenology, 9, 1-12. http://dx.doi .org/10.1080/20797222.2009.11433992

Ayalon, L., Shiovitz-Ezra, S., \& Palgi, Y. (2012). No place like home? Potential pathways to loneliness in older adults under the care of a live-in foreign home care worker. The Journal of Psychology: Interdisciplinary and Applied, 146, 189-200. http://dx.doi.org/10.1080/00223980.2011.574169

Ballard, J. (2010). Forgetfulness and older adults: Concept analysis. Journal of Advanced Nursing, 66, 1409-1419. http://dx.doi.org/10.1111/j.13652648.2010.05279.x

Bekhet, A. K., Zauszniewski, J. A., \& Nakhla, W. E. (2008). Loneliness: A concept analysis. Nursing Forum, 43, 207-213. http://dx.doi.org/10.1111/j .1744-6198.2008.00114.x

Bonell, C., Hinds, K., Dickson, K., Thomas, J., Fletcher, A., Murphy, S., . . Campbell, R. (2016). What is positive youth development and how might it reduce substance use and violence? A systematic review and synthesis of theoretical literature. BMC Public Health, 16, 135. http://dx.doi .org/10.1186/s12889-016-2817-3

Boomsma, D. I., Willemsen, G., Dolan, C. V., Hawkley, L. C., \& Cacioppo, J. T. (2005). Genetic and environmental contributions to loneliness in adults: The Netherlands twin register study. $B e$ havior Genetics, 35, 745-752. http://dx.doi.org/10 .1007/s10519-005-6040-8
Bowlby, J. (1973). Attachment and loss (Vol. 2). New York, NY: Basic Books.

Bronfenbrenner, U. (1992). Ecological systems theory. London, United Kingdom: Jessica Kingsley Publishers.

Cacioppo, J. T., Cacioppo, S., \& Boomsma, D. I. (2014). Evolutionary mechanisms for loneliness. Cognition and Emotion, 28, 3-21. http://dx.doi .org/10.1080/02699931.2013.837379

Cacioppo, J. T., Ernst, J. M., Burleson, M. H., McClintock, M. K., Malarkey, W. B., Hawkley, L. C., . . . Berntson, G. G. (2000). Lonely traits and concomitant physiological processes: The MacArthur social neuroscience studies. International Journal of Psychophysiology, 35, 143-154. http:// dx.doi.org/10.1016/S0167-8760(99)00049-5

Cacioppo, J. T., Fowler, J. H., \& Christakis, N. A. (2009). Alone in the crowd: The structure and spread of loneliness in a large social network. Journal of Personality and Social Psychology, 97, 977-991. http://dx.doi.org/10.1037/a0016076

Cacioppo, J. T., \& Hawkley, L. C. (2009). Perceived social isolation and cognition. Trends in Cognitive Sciences, 13, 447-454. http://dx.doi.org/10.1016/j .tics.2009.06.005

Cacioppo, J. T., Hawkley, L. C., Ernst, J. M., Burleson, M. H., Berntson, G. G., Nouriani, B., \& Spiegel, D. (2006). Loneliness within a nomological net: An evolutionary perspective. Journal of Research in Personality, 40, 1054-1085. http://dx.doi .org/10.1016/j.jrp.2005.11.007

Cacioppo, S., Capitanio, J. P., \& Cacioppo, J. T. (2014). Toward a neurology of loneliness. Psychological Bulletin, 140, 1464-1504. http://dx.doi .org/10.1037/a0037618

Choi, B. C., \& Pak, A. W. (2006). Multidisciplinarity, interdisciplinarity and transdisciplinarity in health research, services, education and policy: 1 . Definitions, objectives, and evidence of effectiveness. Clinical and Investigative Medicine, 29, 351-364.

Dahlberg, K. (2007). The enigmatic phenomenon of loneliness. International Journal of Qualitative Studies on Health and Well-being, 2, 195-207. http://dx.doi.org/10.1080/17482620701626117

de Jong Gierveld, J. (1998). A review of loneliness: Concept and definitions, determinants and consequences. Reviews in Clinical Gerontology, 8, 7380. http://dx.doi.org/10.1017/S0959259898008090 de Jong Gierveld, J., \& Tesch-Römer, C. (2012a). Loneliness in old age in Eastern and Western European societies: Theoretical perspectives. European Journal of Ageing, 9, 285-295. http://dx.doi .org/10.1007/s10433-012-0248-2

Derlega, V. J., \& Margulis, S. T. (1982). Why loneliness occurs: The interrelationship of socialpsychological and privacy concepts. In L. A. Peplau \& D. Perlman (Eds.), Loneliness: A sourcebook 
of current theory, research and therapy (pp. 152165). New York, NY: Wiley.

DiTommaso, E., Brannen, C., \& Burgess, M. (2005). The universality of relationship characteristics: A cross-cultural comparison of different types of attachment and loneliness in Canadian and visiting Chinese students. Social Behavior and Personality, 33, 57-68. http://dx.doi.org/10.2224/sbp.2005 .33.1.57

Dolezal, L. (2015). The body and shame: Phenomenology, feminism and the socially shaped body. Lanham, MD: Lexington Books.

Dolezal, L., \& Petherbridge, D. (2017). Body/self/ other: The phenomenology of social encounters. Albany, NY: SUNY Press.

Eisenberger, N. I., Lieberman, M. D., \& Williams, K. D. (2003). Does rejection hurt? An FMRI study of social exclusion. Science, 302, 290-292. http:// dx.doi.org/10.1126/science. 1089134

ElSadr, C. B., Noureddine, S., \& Kelley, J. (2009). Concept analysis of loneliness with implications for nursing diagnosis. International Journal of Nursing Terminologies and Classifications, 20, 25-33. http://dx.doi.org/10.1111/j.1744-618X .2008.01110.x

Findlay, R. A. (2003). Interventions to reduce social isolation amongst older people: Where is the evidence? Ageing and Society, 23, 647-658. http://dx .doi.org/10.1017/S0144686X03001296

Fromm-Reichmann, F. (1959). Loneliness. Psychiatry: Interpersonal and Biological Processes, 22, 1-15. http://dx.doi.org/10.1080/00332747.1959 .11023153

Galanaki, E. P., \& Vassilopoulou, H. D. (2007). Teachers and children's loneliness: A review of the literature and educational implications. European Journal of Psychology of Education, 22, 455-475. http://dx.doi.org/10.1007/BF03173466

Gallagher, S. (2014). The cruel and unusual phenomenology of solitary confinement. Frontiers in Psychology, 5, 585.

Gardiner, C., Geldenhuys, G., \& Gott, M. (2018). Interventions to reduce social isolation and loneliness among older people: An integrative review. Health and Social Care in the Community, 26, 147-157. http://dx.doi.org/10.1111/hsc.12367

Green, B. H., Copeland, J. R., Dewey, M. E., Sharma, V., Saunders, P. A., Davidson, I. A., . . . McWilliam, C. (1992). Risk factors for depression in elderly people: A prospective study. Acta Psychiatrica Scandinavica, 86, 213-217. http://dx.doi .org/10.1111/j.1600-0447.1992.tb03254.x

Guenther, L. (2013). Solitary confinement: Social death and its afterlives. Minneapolis: Minnesota University Press. http://dx.doi.org/10.5749/ minnesota/9780816679584.001.0001

Hawkley, L. C., \& Cacioppo, J. T. (2010). Loneliness matters: A theoretical and empirical review of con- sequences and mechanisms. Annals of Behavioral Medicine, 40, 218-227. http://dx.doi.org/10.1007/ s12160-010-9210-8

Hawkley, L. C., \& Capitanio, J. P. (2015). Perceived social isolation, evolutionary fitness, and health outcomes: A lifespan approach. Philosophical Transactions of the Royal Society, 370, 20140114. http://dx.doi.org/10.1098/rstb.2014.0114

Hawkley, L. C., Preacher, K. J., \& Cacioppo, J. T. (2007). Multilevel modeling of social interactions and mood in lonely and socially connected individuals: The MacArthur social neuroscience studies. In A. D. Ong \& M. van Dulmen (Eds.), Oxford handbook of methods in positive psychology (pp. 559-575). New York, NY: Oxford University Press.

Hawkley, L. C., Thisted, R. A., Masi, C. M., \& Cacioppo, J. T. (2010). Loneliness predicts increased blood pressure: 5-year cross-lagged analyses in middle-aged and older adults. Psychology and Aging, 25, 132-141. http://dx.doi.org/10.1037/ a0017805

Heinrich, L. M., \& Gullone, E. (2006). The clinical significance of loneliness: A literature review. Clinical Psychology Review, 26, 695-718. http:// dx.doi.org/10.1016/j.cpr.2006.04.002

Høffding, S., \& Martiny, K. (2016). Framing a phenomenological interview: What, why and how. Phenomenology and the Cognitive Sciences, 15, 539-564. http://dx.doi.org/10.1007/s11097-0159433-Z

Holt-Lunstad, J., Smith, T. B., Baker, M., Harris, T., \& Stephenson, D. (2015). Loneliness and social isolation as risk factors for mortality: A metaanalytic review. Perspectives on Psychological Science, 10, 227-237. http://dx.doi.org/10.1177/ 1745691614568352

Houlihan, S. (2018). Dual-process models of healthrelated behaviour and cognition: A review of theory. Public Health, 156, 52-59. http://dx.doi.org/ 10.1016/j.puhe.2017.11.002

Husserl, E. (1977). Cartesian meditations: An introduction to phenomenology (Translated by $\mathrm{D}$. Cairns). Dordrecht, the Netherlands: Kluwer Academic Publishers. http://dx.doi.org/10.1007/97894-009-9997-8

Iecovich, E., Barasch, M., Mirsky, J., Kaufman, R., Avgar, A., \& Kol-Fogelson, A. (2004). Social support networks and loneliness among elderly Jews in Russia and Ukraine. Journal of Marriage and Family, 66, 306317. http://dx.doi.org/10.1111/j.1741-3737.2004 .00022.x

Jackson, J., \& Cochran, S. D. (1991). Loneliness and psychological distress. The Journal of Psychology: Interdisciplinary and Applied, 125, 257-262. http://dx.doi .org/10.1080/00223980.1991.10543289

Johnson, D. P., \& Mullins, L. C. (1987). Growing old and lonely in different societies: Toward a com- 
parative perspective. Journal of Cross-Cultural Gerontology, 2, 257-275. http://dx.doi.org/10 $.1007 / \mathrm{BF} 00160684$

Kupersmidt, J. B., Sigda, K. B., Sedikides, C., \& Voegler, M. E. (1999). Social self-discrepancy theory and loneliness during childhood and adolescence. In K. J. Rotenberg \& S. Hymel (Eds.), Loneliness in childhood and adolescence (pp. 263-279). Cambridge, United Kingdom: Cambridge University Press.

Lawlor, B. A., Golden, J., Paul, G., Walsh, C., Conroy, R. M., Holfield, E., \& Tobin, M. (2014). Only the Lonely: A randomised controlled trial of $a$ volunteer visiting programme for older people experiencing loneliness. Dublin, Ireland: Age Friendly Ireland. http://dx.doi.org/10.13140/2.1 .2468 .0007

Levinas, E. (1987). Time and the Other. Pittsburgh, PA: Duquesne University Press.

Lykes, V. A., \& Kemmelmeier, M. (2014). What predicts loneliness? Cultural difference between individualistic and collectivistic societies in Europe. Journal of Cross-Cultural Psychology, 45, 468-490. http://dx.doi.org/10.1177/ 0022022113509881

Mahon, N. E., Yarcheski, A., Yarcheski, T. J., Cannella, B. L., \& Hanks, M. M. (2006). A metaanalytic study of predictors for loneliness during adolescence. Nursing Research, 55, 308-315. http://dx.doi.org/10.1097/00006199-20060900000003

Marangoni, C., \& Ickes, W. (1989). Loneliness: A theoretical review with implications for measurement. Journal of Social and Personal Relationships, 6, 93-128. http://dx.doi.org/10.1177/ 026540758900600107

Masi, C. M., Chen, H. Y., Hawkley, L. C., \& Cacioppo, J. T. (2011). A meta-analysis of interventions to reduce loneliness. Personality and Social Psychology Review, 15, 219-266. http://dx.doi .org/10.1177/1088868310377394

Matthews, G. A., Nieh, E. H., Vander Weele, C. M., Halbert, S. A., Pradhan, R. V., Yosafat, A. S., . . . Tye, K. M. (2016). Dorsal raphe dopamine neurons represent the experience of social isolation. Cell, 164, 617-631. http://dx.doi.org/10.1016/j .cell.2015.12.040

Mayers, A. M., \& Svartberg, M. (2001). Existential loneliness: A review of the concept, its psychosocial precipitants and psychotherapeutic implications for HIV-infected women. British Journal of Medical Psychology, 74, 539-553. http://dx.doi .org/10.1348/000711201161082

McHugh Power, J. E., Hannigan, C., Carney, S., \& Lawlor, B. A. (2017). Exploring the meaning of loneliness among socially isolated older adults in rural Ireland: A qualitative investigation. Qualita- tive Research in Psychology, 14, 394-414. http:// dx.doi.org/10.1080/14780887.2017.1329363

Merleau-Ponty, M. (2012). Phenomenology of Perception (Translated by Donald A. Landes). London, United Kingdom: Routledge.

Michie, S., \& Prestwich, A. (2010). Are interventions theory-based? Development of a theory coding scheme. Health Psychology, 29, 1-8. http://dx.doi .org/10.1037/a0016939

Mikulincer, M., \& Shaver, P. R. (2014). An attachment perspective on loneliness. In R. J. Coplan \& J. C. Bowker (Eds.), The handbook of solitude: Psychological perspectives on social isolation, social withdrawal, and being alone (pp. 34-50). Hoboken, NJ: Wiley.

Moustakas, C. E. (1961). Loneliness. New York, NY: Prentice Hall.

Nilsson, B., Lindström, U. Å., \& Nåden, D. (2006). Is loneliness a psychological dysfunction? A literary study of the phenomenon of loneliness. Scandinavian Journal of Caring Sciences, 20, 93-101. http://dx.doi.org/10 .1111/j.1471-6712.2006.00386.x

O'Luanaigh, C., O'Connell, H., Chin, A. V., Hamilton, F., Coen, R., Walsh, C., . . . Lawlor, B. A. (2012). Loneliness and vascular biomarkers: The Dublin healthy ageing study. International Journal of Geriatric Psychiatry, 27, 83-88. http://dx.doi .org/10.1002/gps.2695

Ong, A. D., Uchino, B. N., \& Wethington, E. (2016). Loneliness and health in older adults: A minireview and synthesis. Gerontology, 62, 443-449. http://dx.doi.org/10.1159/000441651

Paley, J. (2016). Phenomenology as qualitative research: A critical analysis of meaning attribution. London, United Kingdom: Routledge.

Parnas, J., Møller, P., Kircher, T., Thalbitzer, J., Jansson, L., Handest, P., \& Zahavi, D. (2005). EASE: Examination of anomalous self-experience. Psychopathology, 38, 236-258. http://dx.doi.org/ 10.1159/000088441

Peplau, L. A., \& Perlman, D. (1982). Perspectives on loneliness. In L. A. Peplau \& D. Perlman (Eds.), Loneliness: A sourcebook of current theory, research and therapy (pp. 1-20). New York, NY: John Wiley \& Sons.

Perlman, D. (2004). European and Canadian studies of loneliness among seniors. Canadian Journal on Aging, 23, 181-188. http://dx.doi.org/10.1353/cja .2004 .0025

Perlman, D., \& Peplau, L. A. (1982). Theoretical approaches to loneliness. In L. A. Peplau \& D. Perlman (Eds.), Loneliness: A sourcebook of current theory, research and therapy (pp. 123-134). New York, NY: John Wiley \& Sons.

Pound, P., \& Campbell, R. (2015). Exploring the feasibility of theory synthesis: A worked example in the field of health related risk-taking. Social Science \& Medicine, 124, 57-65. 
Pietkiewicz, I., \& Smith, J. A. (2014). A practical guide to using interpretative phenomenological analysis in qualitative research psychology. Psychological Journal, 20, 7-14.

Prestwich, A., Sniehotta, F. F., Whittington, C., Dombrowski, S. U., Rogers, L., \& Michie, S. (2014). Does theory influence the effectiveness of health behavior interventions? Meta-analysis. Health Psychology, 33, 465-474. http://dx.doi .org/10.1037/a0032853

Qualter, P., Vanhalst, J., Harris, R., Van Roekel, E., Lodder, G., Bangee, M., . . . Verhagen, M. (2015). Loneliness across the life span. Perspectives on Psychological Science, 10, 250-264. http://dx.doi .org/10.1177/1745691615568999

Ratcliffe, M. (2014). Experiences of depression: A study in phenomenology. Oxford, United Kingdom: Oxford University Press.

Rokach, A. (1988). The experience of loneliness: A tri-level model. The Journal of Psychology: Interdisciplinary and Applied, 122, 531-544. http://dx .doi.org/10.1080/00223980.1988.9915528

Rokach, A., Rosenstreich, E., \& Matot, I. (2015). Loneliness and sense of coherence in pre-operative patients. International Journal of Psychological Research, 9, 207-235.

Rosedale, M. (2007). Loneliness: An exploration of meaning. Journal of the American Psychiatric Nurses Association, 13, 201-209. http://dx.doi .org/10.1177/1078390307306617

Salice, A., \& Schmid, H. B. (2016). The phenomenological approach to social reality: History, concepts, problems. Basel, Switzerland: Springer International Publishing. http://dx.doi.org/10.1007/ 978-3-319-27692-2

Sartre, J. P. (2003). Being and nothingness: An essay on phenomenological ontology (Translated by Hazel E. Barnes). London, United Kingdom: Routledge.

Scharf, T., \& de Jong Gierveld, J. (2008). Loneliness in urban neighbourhoods: An Anglo-Dutch comparison. European Journal of Ageing, 5, 103-115. http://dx.doi.org/10.1007/s10433-008-0080-x

Schirmer, W., \& Michailakis, D. (2016). Loneliness among older people as a social problem: The perspectives of medicine, religion, and economy. Ageing and Society, 36, 1559-1579. http://dx.doi .org/10.1017/S0144686X15000999

Slater, P. E. (1970). The pursuit of loneliness: American culture at the breaking point. Boston, MA: Beacon Press.

Sønderby, L. C., \& Wagoner, B. (2013). Loneliness: An integrative approach. Journal of Integrated Social Sciences, 3, 1-29.

Spithoven, A. W. M., Bijttebier, P., \& Goossens, L. (2017). It is all in their mind: A review on information processing bias in lonely individuals. Clin- ical Psychology Review, 58, 97-114. http://dx.doi .org/10.1016/j.cpr.2017.10.003

Stein, J. Y., \& Tuval-Mashiach, R. (2015). The social construction of loneliness: An integrative conceptualization. Journal of Constructivist Psychology, 28, 210-227. http://dx.doi.org/10.1080/10720537 .2014 .911129

Sullivan, H. S. (1953). The interpersonal theory of psychiatry. New York, NY: Tavistock Press.

Szanto, T., \& Moran, D. (2016). Phenomenology of sociality: Discovering the 'We. London, United Kingdom: Routledge.

Terwee, C. B., Mokkink, L. B., Knol, D. L., Ostelo, R. W. J. G., Bouter, L. M., \& de Vet, H. C. W. (2012). Rating the methodological quality in systematic reviews of studies on measurement properties: A scoring system for the COSMIN checklist. Quality of Life Research: An International Journal of Quality of Life Aspects of Treatment, Care and Rehabilitation, 21, 651-657. http://dx .doi.org/10.1007/s11136-011-9960-1

Theeke, L. A. (2009). Predictors of loneliness in U.S. adults over age sixty-five. Archives of Psychiatric Nursing, 23, 387-396. http://dx.doi.org/10.1016/j .apnu.2008.11.002

Theeke, L. A., Mallow, J. A., Moore, J., McBurney, A., Rellick, S., \& VanGilder, R. (2016). Effectiveness of LISTEN on loneliness, neuroimmunological stress response, psychosocial functioning, quality of life, and physical health measures of chronic illness. International Journal of Nursing Sciences, 3, 242-251. http://dx.doi.org/10.1016/j.ijnss.2016 .08 .004

Thurston, R. C., \& Kubzansky, L. D. (2009). Women, loneliness, and incident coronary heart disease. Psychosomatic Medicine, 71, 836-842. http://dx.doi.org/10.1097/PSY.0b013e3181b40efc

Tzouvara, V., Papadopoulos, C., \& Randhawa, G. (2015). A narrative review of the theoretical foundations of loneliness. British Journal of Cоттиnity Nursing, 20, 329-334. http://dx.doi.org/10 $.12968 /$ bjen.2015.20.7.329

Valtorta, N. K., Kanaan, M., Gilbody, S., Ronzi, S., \& Hanratty, B. (2016). Loneliness and social isolation as risk factors for coronary heart disease and stroke: Systematic review and meta-analysis of longitudinal observational studies. Heart, 102, 1009-1016. http://dx.doi.org/10.1136/heartjnl2015-308790

van Staden, W. C. W., \& Coetzee, K. (2010). Conceptual relations between loneliness and culture. Current Opinion in Psychiatry, 23, 524-529. http://dx.doi.org/10.1097/YCO.0b013e32833f2ff9 van Tilburg, T., Havens, B., \& de Jong Gierveld, J. (2004). Loneliness among older adults in The Netherlands, Italy, and Canada: A multifaceted comparison. Canadian Journal on Aging, 23, 169180. http://dx.doi.org/10.1353/cja.2004.0026 
Weiss, R. S. (1973). Loneliness: The experience of emotional and social isolation. Cambridge, MA: The MIT Press.

Weiss, R. (1974). The provision of social relationships. In Z. Rubin (Ed.), Doing unto others (pp. 17-26). Upper Saddle River, NJ: Prentice Hall.

Wight, D., Wimbush, E., Jepson, R., \& Doi, L. (2015). Six steps in quality intervention development (6SQuID). Journal of Epidemiology and Community Health, 70, 520-525. http://dx.doi.org/ 10.1136/jech-2015-205952

Wilson, R. S., Krueger, K. R., Arnold, S. E., Schneider, J. A., Kelly, J. F., Barnes, L. L., . . . Bennett, D. A. (2007). Loneliness and risk of Alzheimer disease. Archives of General Psychiatry, 64, 234240. http://dx.doi.org/10.1001/archpsyc.64.2.234

Wong, N. M. L., Yeung, P. P. S., \& Lee, T. M. C. (2018). A developmental social neuroscience model for understanding loneliness in adolescence. Social Neuroscience, 13, 94-103. http://dx.doi .org/10.1080/17470919.2016.1256832
Wong, Q. J. J., \& Rapee, R. M. (2016). The aetiology and maintenance of social anxiety disorder: A synthesis of complementary theoretical models and formulation of a new integrated model. Journal of Affective Disorders, 203, 84-100.

Zahavi, D. (2014). Self and other: Exploring subjectivity, empathy and shame. Oxford, United Kingdom: Oxford University Press. http://dx.doi.org/10 .1093/acprof:oso/9780199590681.001.0001

Zysberg, L. (2015). Emotional antecedents of psychological loneliness: A review and an emerging model. In D. L. Rhodes (Ed.), Loneliness: Psychosocial risk factors, prevalence and impacts on physical and emotional health (pp. 57-72). Hauppauge, NY: Nova Science Publishers.

Received November 21, 2017

Revision received March 3, 2018 Accepted June 12, 2018

\section{E-Mail Notification of Your Latest Issue Online!}

Would you like to know when the next issue of your favorite APA journal will be available online? This service is now available to you. Sign up at https://my.apa.org/ portal/alerts/ and you will be notified by e-mail when issues of interest to you become available! 